\title{
Modeling Thermal Enrichment of Streams due to Solar Heating of Local Urban Stormwater
}

\author{
William James and Jennifer D. M. Xie
}

This chapter presents a computation of the thermal enrichment of streams due to local urban stormwater. Our earlier study (Xie and James, 1994) confirmed that thermal enrichment is a critical stressor of aquatic habitats and ecology downstream of urban areas. Previous workers had found a linear relationship between percentage imperviousness and observed thermal enrichment (\%I- $\Delta \mathrm{T})$ ). Here we apply the Hydrological Simulation Program-Fortran (HSPF) to the Speed River at Guelph to check that relationship.

We found that the HSPF processes for heat buildup/wash-off from impervious, urban surfaces during hot weather are somewhat deficient for this work. A simple experiment in a parking lot at the School of Engineering confirmed the importance of these processes. Results were used to re-calibrate HSPF against a large data set collected from various sources for the Speed River at Guelph.

Evidently, this is the first: (i) application of HSPF to examine thermal enrichment due to urban developments; (ii) reproduction of the general linear $\% \mathrm{I}-\Delta \mathrm{T}$ relation using a comprehensive theoretical model; and (iii) application of a model of thermal enrichment of urban streams, treating a large urban area as a solar receptor. Several recommendations are made for developing models of heat in runoff. It is suggested that more experiments, such as those described by James and Verspagen (1996) and Picksley and Deletic (1998), are required.

James, W. and J. Xie. 1999. "Modeling Thermal Enrichment of Streams due to Solar Heating of Local Urban Stormwater." Journal of Water Management Modeling R204-08. doi: 10.14796/JWMM.R204-08. (C) CHI 1999 www.chijournal.org ISSN: 2292-6062 (Formerly in New Applications in Modeling Urban Water Systems. ISBN: 0-9697422-9-0) 


\subsection{Introduction}

Through the process of urbanization, vegetation is removed from watersheds, formerly pervious surfaces (such as rooftops, streets and parking lots) are rendered impermeable and natural drainage networks are modified to convey runoff more efficiently. We term the increase in heat content of runoff, over what it would have been had there been no development, "thermal enrichment". Note here that we assume that the pre-development situation is the original mixed hardwood forest with full canopy, rather than (for example) agricultural development with exposed soil. Note also that the amount of runoff, which carries with it the increased heat content, is itself increased by urbanization, and that this further contributes to thermal enrichment of receiving waters. These processes act together to alter the thermal regime of urban headwater streams (Galli, 1990).

Thermal enrichment of stormwater has been, and clearly remains, one of most important effects of urbanization. It destroys fish and aquatic ecosystems, and affects other indicators, like oxygen concentration or pollutant concentration, because of the temperature dependence of many related processes. The association between thermal enrichment and percentage imperviousness is well known; in fact, previous workers have established a simple linear relation between these parameters. Development of urban surfaces in watersheds has the greatest influence on the stream temperature of headwater streams. For example, urban stormwater runoff has raised the temperature of summer runoff $5.5^{\circ} \mathrm{C}$ at East Meadow Brook, and $8.5^{\circ} \mathrm{C}$ at Swan River in New York (Pluhowski, 1970). Such thermal enrichment may cause the temperature to rise significantly beyond lethal levels for certain aquatic ecosystems. Water temperature is important not just because of the temperature dependence of many processes and quality indicators, like oxygen concentration or pollutant concentration. Water temperature is a quality indicator per se, affecting the kind of fish in the river, the temperature of the drinking water produced, fog frequency along the river, flow rate, etc. (Chow et al., 1979).

Despite considerable interest in stormwater pollution, very few published studies refer to modeling of the thermal enrichment of stormwater (Shanahan, 1984). Current modeling procedures do not account for heat transported from impervious paved surfaces during hot weather by rainfall runoff. Although there are temperature models, no existing theory and available models adequately simulate urban stormwater thermal enrichment of, nor the impacts on, receiving waters. On the other hand, HSPF is a very comprehensive water quantity and quality model, resulting from some twenty years of process research and model development, testing, refinement, and application (Donigian et al., 1983). Many variables can be input to HSPF including water temperature. For stream temperature, HSPF estimates thermal energy from pervious and impervious lands (by empirical equations), and calculates stream temperature by a heat budget approach. It is, however, extremely onerous to learn to use. 
Objectives of this chapter are to:

1. determine the sensitivity of an HSPF water temperature model to variation in model parameters for summer conditions;

2. calibrate the model for temperature and runoff from urban areas for Ontario summer conditions;

3. check the consistency of the computed results against previously published findings; and

4. recommend modeling methodology and thermal management strategies in urban areas.

The study is limited to hot-weather events. Not covered is an analysis of thermodynamic point processes in pavement during rainfall.

For our background review readers are referred to our earlier chapter (Xie and James, 1994) in this series of monographs.

\subsection{Heat Washoff from a Parking Lot}

First a note: in this discussion the USEPA Stormwater Management Model (SWMM) (Huber and Dickinson, 1988) build-up/wash-off analogy is adopted (James and Boregowda, 1985), even though the approach is unconventional in regard to heat. An experiment was carried out to demonstrate that overland flow due to rain on a warm, impervious surface transports heat that is gained from that surface. During our summer season, when the pavement lies directly in the sun with continuous hot, dry weather, the heat content of pavement increases. Temperatures of the upper skin of impervious surfaces (such as asphalt) can become quite hot. If a storm occurs under such circumstances, the pavement will be washed by the rain and some of the heat in the pavement surface will be transferred into the surface flow, and carried away by runoff. Warm pavement is cooled by rain. An examination of heat build-up/wash-off concepts (borrowed from SWMM) begs several questions:

- How is pavement runoff heated during hot days?

- What is the heat content of the pavement before washoff?

- How much of this heat is transported to the receiver?

- What are the temperature differences between air, rain, runoff, and pavement?

- What, if any, is the relation between air and pavement temperature?

- What, if any, is the relation between runoff temperature and pavement temperature?

- Besides a detailed analysis of the point thermodynamic processes, is there any simpler way to quantify the relations? 
To answer these questions, it was decided that an experiment should be carried out in the parking lot behind the School of Engineering at the University of Guelph. The experiment included two main steps:

1. placement of (i) an artificial rainfall generator on a small watershed (a part of the asphalt pavement) and (ii) a container at the 'downstream' end to collect the runoff, to establish the rainfall-runoff relation, and

2. measurement of temperatures of rainfall, runoff, air, and pavement continuously in order to examine their relationships. Temperatures were sampled every second, but only fifteen-second average temperatures were recorded by the computer, and runoff was sampled minutely. Rain intensities were recorded manually by noting pressure gage and nozzle size.

Results, obtained on a cool day in late Spring, provided answers to most of the questions posed above. Runoff temperature generally increased from 16 to $21^{\circ} \mathrm{C}$, but extremes (differences of about 6 to $10^{\circ} \mathrm{C}$ ) occurred at the onset and cessation of rains. Air temperature varied from 13 to $17^{\circ} \mathrm{C}$, and was affected by many factors, e.g., radiation, wind and cloud. Rain temperature remained fairly constant from 12 to $14^{\circ} \mathrm{C}$ (stored water was used). Wet pavement temperature varied from 15 to $21^{\circ} \mathrm{C}$, maintaining an increasing trend in no-rain durations, because no runoff water was available to transport heat from the pavement. On the other hand, wet pavement temperature showed a decreasing trend in the rain periods.

The runoff water temperature was elevated 4 to $5^{\circ} \mathrm{C}$ (from rainfall to runoff) after heat transfer from the pavement to runoff. At the beginning of the rain event, the elevation was even greater, since pavement temperature was highest before the onset of runoff. The temperature of dry pavement was about 8 to $9^{\circ} \mathrm{C}$ higher than the air temperature, $10^{\circ} \mathrm{C}$ higher than rain temperature, and 6 to $7^{\circ} \mathrm{C}$ higher than runoff temperature. Heat was transferred from pavement to stormwater, and the temperature of wet pavement was $5^{\circ} \mathrm{C}$ lower than that of the dry pavement. Our observation that runoff temperature from exposed impervious pavement was about 1 to $4^{\circ} \mathrm{C}$ higher than air temperature may not apply to flow from pervious land. It was observed that the temperature of the dry pavement was 10 to $14^{\circ} \mathrm{C}$ higher than pervious land (depending on whether the pervious land is shaded or not). Heat accumulation in the upper layer of impervious asphalt pavement is much greater than it is on pervious land. Heat transported from pavement is thus a notable source of thermal enrichment of storrnwater.

Temperatures of the air, rain, dry and wet pavement were recorded continuously even during the times without rain. The results show that pavement temperature was 8 to $9{ }^{\circ} \mathrm{C}$ higher than air temperature at all times. Air and pavement temperatures have similar differences and both are sensitive to rapid changes. However, the ranges of pavement temperature were greater than that of air temperature. 
Air temperature showed more diurnal variation than did runoff temperature. The air and runoff temperature data sets were linearly regressed, and showed quasi-linear relationship between them $\left(R^{2}=0.63\right)$. The relationship is not considered to be strong, probably because the effects of wind transport of thermal energy (wind effects) were not accounted for in this regression.

Runoff and wet pavement temperature series data were regressed for a 15 minute duration. Runoff temperature was dependent, and wet pavement temperature independent. The time step used was a 15 second mean and runoff temperature data were lagged 15 seconds. Using the simplest correlation equation (linear relation):

$$
r=\frac{\sum\left(x_{i}-\bar{x}\right)\left(y_{i}-\bar{y}\right)}{\sqrt{\sum\left(x_{i}-\bar{x}\right)^{2} \sum\left(y_{i}-\bar{y}\right)^{2}}}
$$

and applying different lag times ( \pm 15 seconds, \pm 30 seconds and \pm 45 seconds) in a linear regression analysis, the relationship (r) between runoff temperature and wet pavement temperature shows different values:

Table 8.1 Time lag analysis on wet pavement and runoff temperatures.

\begin{tabular}{llllll}
\hline lag* & r coefficient & constant & Std Err of $Y$ & $x$ coefficient & Std Err of $X$ \\
\hline 0 & 0.885 & 2.8 & 0.2 & 0.855 & 0.04 \\
+15 & 0.9 & 3.3 & 0.18 & 0.828 & 0.036 \\
+30 & 0.883 & 3.9 & 0.19 & 0.789 & 0.037 \\
+45 & 0.884 & 4.2 & 0.18 & 0.771 & 0.036 \\
\hline
\end{tabular}

"lag time unit is seconds; +15 second means that runoff temperature lagged $15 \mathrm{sec}$. behind wet pavement temperature.

The temperature of wet pavement has an excellent linear relationship with runoff temperature:

where:

$$
\mathrm{T}_{\mathrm{R}}=3.26+0.828 \mathrm{~T}_{\mathrm{pw}}
$$

$$
\begin{aligned}
T_{R} & =\text { temperature of runoff } \\
T_{p w} & =\text { temperature of wet pavement }
\end{aligned}
$$

$\mathrm{R}^{2}$ is 0.9 , indicating a good relationship between wet pavement and runoff temperatures. Standard errors of coefficient are very low, indicating a reliable result. Our experiment is considered to have successfully demonstrated that typical urban, impervious asphaltic surfaces increase in temperature during warm days. 
We conclude that the rainfall/runoff process results in heat being transported from the impervious surface to overland flow and thus the receiving waters. Results were significant for the calibration of the HSPF model of the Speed River at Guelph, as described below.

\subsection{Water Temperature Simulation for the Speed River at Guelph}

The Speed River watershed covers approximately $780 \mathrm{~km}^{2}$ to the Grand River at the northwest edge of Cambridge. The Speed River is approximately $60 \mathrm{~km}$ long and has an average longitudinal slope of $0.3 \%$. The main tributary of the Speed River is the Eramosa River, which is approximately $40 \mathrm{~km}$ long at an average channel slope of $0.2 \%$, and drains about $300 \mathrm{~km}^{2}$. The major urban centres in the combined watershed are the Cities of Guelph and Cambridge. The study domain selected is the watershed which falls in the area downstream of Guelph Lake and upstream of the Speed River at Puslinch Lake Road. This area embraces the whole of the City of Guelph. The study area is about $169 \mathrm{~km}^{2}$ of which $128.7 \mathrm{~km}^{2}$ lies in the Speed River watershed and $41.2 \mathrm{~km}^{2}$ in the Eramosa watershed. Two stream reaches were modeled, $16.2 \mathrm{~km}$ of the Speed River, and $6.2 \mathrm{~km}$ of the Eramosa River.

Soil in the area comprises loamy tills and outwash deposits of fine sand and some outwash gravel. There are deposits of organic soils in depressions, particularly in the swampy valleys between drumlins. Most of the upland soils have high infiltration ability and produce overland runoff only rarely, e.g., during very high intensity rain or during runoff episodes when soils are frozen with a high water content. Less than half of the study area is urban, comprising the City of Guelph, with a population in 1991 of 87,976 (Statistics Canada Census Divisions and Subdivisions, 1991), and an area of $68.71 \mathrm{~km}^{2}$. The rest of the area is rural or wooded. Discharge from the Guelph Sewage Treatment Plant (downstream of the city of Guelph) was considered to be a point source of heat into the Speed River, that had to be accounted for.

HSPF requires significant effort for assimilating necessary input data. Prodigious data management efforts are required, but not detailed here. Version 9 of the HSPF model was applied; the following are its highlights: code comprised about 100,000 lines of mixed Fortran source code, arranged in about 550 routines. The compilation, linking, installation and use of software of this complexity was considered to be at the limit of the hardware and utilities available on personal computers at the time of this study (1991-3). The PC used was a 8086 machine upgraded with 80386 chips. The scope of HSPF is considered to be very wide: the user's manual is over 900 pages long and covers many application areas (hydrology, micrometeorology, soil physics, hydraulics, fluid mechanics, aquatic 
chemistry, snow hydrology, groundwater, etc.). Familiarity with the model is considered to be a challenge; the complexity of HSPF cannot be adequately described here, and readers are referred to the manual (Johanson et al., 1984).

For simplicity in the water temperature simulation, the research area was divided into four segments, since there were two different sub-watersheds, the Speed River and Eramosa River, each with two land uses, urban and rural. All were assumed to have the same meteorological and soil conditions. These four segments were separately simulated by the PERLND and IMPLND modules of HSPF: PERLND was used to simulate rural and wooded land; IMPLND was used to simulate the impervious land in the urban area of Guelph. The RCHRES module was used to simulate the two reaches, the Speed River and the Eramosa River. The following procedures (Johanson et al., 1984), were considered during the simulation:

A. collected data:

- meteorological: solar radiation; air temperature; wind speed, cloud cover; precipitation; and dew point.

- hydrological: stream flow; stream temperature; sewage discharge; river slope; river shape; relationship between discharge and stage;

- watershed data: land use; urban development; impervious and pervious land areas; any possible heat sources discharging into the rivers.

B. heat inputs:

- heat from upstream carried by the Speed River and Eramosa River inflow;

- heat from the Guelph sewage treatment discharge;

- heat from land segments PERLND and IMPLND transported into RCHRES;

C. parameters for the simulation:

- in the PERLND module:

LZSN (lower zone nominal water runoff rate);

INFILT (infiltration capacity of soil);

UZSN ( upper zone nominal water temperature);

LZETP (lower zone ET parameter, an index to density of deeprooted vegetation);

ASLT (surface layer temperature when air temperature is $0^{\circ} \mathrm{C}$ );

BSLT (slope of surface layer temperature regression equation).

- in the IMPLND module:

RETSC (retention-interception storage capability of surface);

AWTF (surface water temperature, when air temperature is $0^{\circ} \mathrm{C}$ );

$\mathrm{BWTF}$ (slope of the surface water temperature regression equation).

- in RCHRES module:

CFSAEX (correction for solar radiation);

KATRAD (longwave radiation coefficient); 
KCOND (conduction-convection heat transport coefficient);

KEVAP (evaporation coefficient).

Investigation of the sensitivity of model parameters is an integral and vital part of the modeling process. Sensitive parameters were ranked so that better care could be exercised in their measurement or estimation. This is especially important for HSPF, which contains thousands of input parameters. Parameter sensitivity is measured by the change in the model output that results when a given parameter is changed by a small amount, while all other parameters are kept constant. Changing expected values of a parameter by $\pm 15 \%$ is a common heuristic method used in sensitivity analysis. Even though a heuristic method was used, sensitivity analysis in this study was a non-trivial task; the 37 parameters tested required over 300 model runs. The analysis was computed for all parameters in all active modules and sub-modules. Of the 22 output time series (TS), only flow and temperature were tested. To rank the sensitive parameters, $\pm 15 \%$ of the range (difference between maximum and minimum expected of values parameters) was set about the expected value. The values of parameters used in this sensitivity analysis are mostly taken from the ARM documentation (Donigian and Davis, 1978), and NPS documentation (Donigian, and Crawford, 1976), or other studies. Since there are not enough application reports of the HSPF model available, some parameters were necessarily crudely estimated.

Parameters LZSN, LZETP, UZSN and AGWRC were most sensitive for the water balance in PWATER. They affect not only the total amount of water but also the peak flow. The INFILT parameter affects the surface and ground water partition and runoff timing. The parameters LSUR, NSUR, SLSUR affect the runoff timing and type. The parameters CFSAEX, KATRAD, and KCOND are sensitive parameters for water temperature. They indicate solar radiation (includes shading level), Iongwave radiation and conduction-convection of heat.

According to this sensitivity analyses, the parameters that affect the outcome of the simulation are: INFILT, UZSN, LZSN, AGWRC and LZETP for runoff or hydrographs and CFSAEX, KATRAD, KCOND and KEVAP for stream temperatures. Other parameters, e.g. RETS, SURS, TW and AIRTEM, had a minor influence on calibration runs, and were assigned their expected values. Since the rank order of sensitive parameters will vary with each application, the results of this study are appropriate in only one particular case.

If a study objective is to predict the absolute input loads in the form of a TS to a receiving water quality model, local site-specific data will probably be required (Huber, 1992). Without calibration data, modeling holds little or no advantage over simple monitoring programs. McCutcheon (1989). Calibration in this study includes the comparison of both monthly and annual values and individual storm events. The calibration is divided into two parts: land surface calibration and instream calibration. The main interest in this study is runoff and 
water temperature simulation, so that in land surface calibration (PERLND, IMPLND), the first step is to adjust hydrologic calibration parameters and initial conditions if necessary, to improve agreement between simulated monthly and annual runoff and observed values.

To compute water balance on an annual basis, the sensitive parameters that govern this balance are LZSN, INFILT, and LZETP. Since the major portion of computed evapotranspiration occurs from the lower soil moisture zone, increasing LZSN will increase computed evapotranspiration and decrease annual runoff. As LZETP is evaluated as the fraction of the watershed with deep rooted vegetation, increasing LZETP will increase computed evapotranspiration and vice versa. The INFILT parameter can also assist in deriving an annual water balance. Since INFILT governs the division of precipitation into various components, increasing WFILT will decrease the surface runoff zone and increase the transfer of water to the lower zone and groundwater, and the total runoff may not change very much. Decreasing INFILT will generally reduce computed evapotranspiration and increase surface runoff (Donigian et al. 1984).

After an annual water balance is obtained, the monthly distribution of runoff can be adjusted using INFILT, the infiltration parameter. Of the various hydrologic components, groundwater is often the easiest to identify. In the watershed studied, with a continuous base flow and groundwater components, increasing INFILT will reduce immediate surface runoff (including interflow) and increase the groundwater component. In this way, runoff is delayed and occurs later in the season as an increased groundwater or base flow. Proper fit of hydrographs for selected storm events can be effectively altered with the UZSN and INTFW parameters. The parameter INTFW has little effect on runoff volumes. Increasing INTFW will reduce peak flows and prolong the recession limb of the hydrograph. The UZSN parameter also affects the hydrograph shape. Decreasing UZSN will generally increase flows especially during the initial portions, or rising limb, of the hydrograph (Donigian et al., 1984).

In the study catchment, the Speed River and the Eramosa River reaches have very different characteristics. The latter has a high proportion of groundwater, so the parameters mentioned above were calibrated in two separate groups, as applicable. Larger values of INFILT and AGWRC were assigned in the Eramosa River reach simulation run.

The initial values for all parameters in the RCHRES sub-model were chosen by either using default values or observed data (such as air and water temperatures). For the hydraulic simulation run, the most important step is to adjust FTABLE values. In this study, FTABLE data were provided by WSC (Water Survey of Canada) and the Grand River Conservation Authority (GRCA).

In performing a calibration run for water temperature simulation, there are four sensitive parameters which strongly influence water temperatures: CFSAEX. KATRAD, KCOND and KEVAP. The most sensitive of the four water temperature calibration parameters is CFSAEX, the ratio of the shortwave radiation incident 
to a reach to the radiation incident at the recording station. Because the Speed River is a wide, open stream, the value of CFSAEX used in the modeling was set to be larger than the model default value, and this gave a better fit to the observed data. Long-wave radiation coefficient KATRAD and conduction-convection heat transport coefficient KCOND were also set larger than the default values, which also provided better calibration results.

Donigian et al. (1984) stated that an adequate calibration is highly dependent on the specific watershed, data conditions, and problems analyzed. Little quantitative information exists to provide experience in applying HSPF and related models and in the framework of this study, the following general guidelines for calibration were used:

\begin{tabular}{lccc} 
& \multicolumn{3}{c}{ Calibration Results } \\
& Very Good & Good & Fair \\
Hydrology/hydraulics & $<10 \%$ & $10-15 \%$ & $15-25 \%$ \\
Sediment & $<15 \%$ & $15-25 \%$ & $25-35 \%$ \\
Water Quality & $<20 \%$ & $20-30 \%$ & $30-40 \%$
\end{tabular}

The terms "very good", "good" and "fair" are based on Donigian's work (1984), and are meant to be non-quantitative, i.e. fuzzy terms. The calibration was run continuously using the nine month hourly data for 1988 . The result for annual time series (February - October) predicted a runoff volume difference (between simulated and recorded values) of less than $3 \%$ which is considered to be very good. Results for monthly runoff values were not as good, but most are in the range "good" or "fair". The first simulation period (February to middle of March, 1988) result was the initial period when snow melt occurred and is not part of this study (SNOW melt processes are not modeled in this study). The second period (middle of March to beginning of May) had an excellent outcome, not only for volume of runoff but also hydrograph shape. The third simulation period (May to June) includes an apparent difference in an event where computed values are much higher than observed data. A dry period (June to August) occurred. There was little rain in June, and not much in July. This period produced the greatest difference between observed and simulated records. The calibration results from August to October showed good agreement in both volume and shape.

Groundwater discharge (or base flow) was consistently over-estimated through the whole year. The following might be the causes: (i) parameters in groundwater simulation such as INFILT and LZETP may be wrongly estimated; (ii) the ratio of PERLND to IMPLND areas may need to be improved (in the study, the watershed areas are estimated from a 1:250000 map); and (iii) other meteorological and hydrological parameters (particularly groundwater) require better knowledge. 
However, calibration of storm events is the central concern here. The largest storm in 1988 was in March and April and probably included snow melt. Of the other storms, one was in May, and the others in August to October. Most of the computed storm events fit well with observed data both in terms of volumes and hydrograph shapes. In general we may conclude that computed surface runoff displayed a good fit. However, it is clear that the computed results are higher than the observed data, especially during the dry period and the summer storm period.

One of the possible reasons for the differences between observed and computed data in the summer (say June to August) was spatially uneven rainfall distributions. In summer 1988, the observed quantity of rainfall was small. It must be noted that storms often occur in an area within the City of Guelph, but miss the rain gage used in the study, which is located at the edge of the City, at the Arboretum. The reverse also applies. In other words, the representativeness of summer thunderstorm rainfall at the one existing gage is highly questionable more rain gages are needed in the watershed.

The water temperature calibration produced a very good result, the difference between annual observed and simulated data being less than $12 \%$ using the Celsius scale. Monthly values also show good agreements. The differences between computed and observed temperature (both yearly and monthly) in degrees $\mathrm{C}$ are less than $20 \%$, which is, as a quality simulation, considered to be "very good" (it would be better using other temperature scales). However, the computed temperatures showed a lower trend than the observed in most cases. The possible causes may be:

1. the impervious area heat transport process is not modeled;

2. computed runoff is higher than observed, which could generate a lower computed temperature;

3. input data are mean monthly values, and therefore miss hot runoff events;

4. the stream temperature is compared 4 miles downstream of Guelph. Water temperature was measured by an instrument where stream water is pumped from the river and thus may be warmer than the water in the river;

5. more work is needed to optimize the parameters;

6. there may be unknown additional heat sources;

7. there may be high computed groundwater exfiltration, which will cool the computed stormwater; and

8. discharge temperature input data from the Guelph Sewage Treatment Plant were estimated from poor records (few values per month), which would also cause modeling inaccuracy.

It was at this point in this study that it was decided to design and carry out the field test in the parking lot, described earlier. As a result of the experiment, input parameters AWTF and BWTF were changed from 0 and 1 to 11.9 and 0.5 
respectively, and the computed results showed a generally improved fit. This was referred to earlier as the re-calibrated model. Stream temperature were recalibrated from four storm events. The water temperature results from four events improved between $7.4 \%$ and $71.6 \%$.

\subsection{Impervious-Area Contributions to Thermal Enrichment}

We have emphasized the point that stream water temperature is highly sensitive to the imperviousness, such as streets, parking lots and roof tops. To reiterate: Galli (1990) found that water temperature in natural streams is greatly influenced by factors such as climate, riparian vegetation, hydrology, topography and stream order/distance from source. Development within natural watersheds sharply increases average stream temperatures in summer and depresses them in winter (Gray and Eddington, 1969; Hewlett and Forston, 1982). Concurrent temperature differences between sites along urban streams have been shown to vary by as much as 7.8 to $11^{\circ} \mathrm{C}$ on hot sunny summer days (Pluhowski, 1970). These large temperature differences have been attributed to a wide variety of urban factors, including the removal of vegetation from stream banks, reduction in the amount of groundwater input to streams, construction of lakes and ponds, increased stormwater runoff to streams, and micro-climate changes associated with increased impervious surfaces such as streets, parking lots, and roof tops (Klein, 1979; Pluhowski, 1970).

To illustrate the relation between increasing temperature and increasing imperviousness $\%$ in a watershed (the \%I- $\Delta \mathrm{T}$ relation described earlier), the HSPF model was run by applying representative percentages of impervious land for the previously described Guelph/Speed River study. Table 8.2 shows the computed results.

The simulation was run hourly from May to September, 1988 , for the Speed River watershed. The results listed above were maximum hourly and daily temperatures and the average values during the five months. Imperviousness percentages were varied from $10 \%$ to $90 \%$. Evidently the computed temperature increased with the watershed imperviousness. Computed hourly maximum $\Delta \mathrm{T}$ increased from 0.5 to $3{ }^{\circ} \mathrm{C}$ when imperviousness increased $10 \%$, while computed daily maximum $\Delta \mathrm{T}$ increased from 0.4 to $1.7^{\circ} \mathrm{C}$. The computed average temperature over five months seemed to change little, a very different result from that shown in the Galli study (1990). Further analysis of model output revealed a strong, linear $\% \mathrm{I}-\Delta \mathrm{T}$ relationship between computed water temperature and input catchment imperviousness:

$$
\begin{aligned}
& \mathrm{T}_{\mathrm{h}}=28.6+0.11 \mathrm{I} \\
& \mathrm{T}_{\mathrm{d}}=25.2+0.09 \mathrm{I} \\
& \mathrm{T}_{\mathrm{s}}=17.0+0.01 \mathrm{I}
\end{aligned}
$$


Table 8.2 Relationship between computed water temperature and watershed imperviousness(\%).

\begin{tabular}{cccc}
\hline$\%$ & Hourly Max & Daily Max & Ave.(May-Sept.) \\
\hline 10 & 27.8 & 25.3 & 17.0 \\
20 & 30.8 & 27.0 & 17.18 \\
30 & 32.7 & 28.0 & 17.32 \\
40 & 34.0 & 29.2 & 17.44 \\
50 & 35.0 & 30.1 & 17.54 \\
60 & 35.8 & 30.9 & 17.63 \\
70 & 36.4 & 31.5 & 17.71 \\
80 & 36.9 & 32.1 & 17.78 \\
90 & 37.4 & 32.5 & 17.84
\end{tabular}

Note: $18 \%$ imperviousness was employed in the Speed River temperature modeling (based on $46 \%$ imperviousness in the Guelph City).

where:

$$
\begin{aligned}
\mathrm{T}_{\mathrm{h}} & =\text { computed hourly max water temperature }{ }^{\circ} \mathrm{C} \\
\mathrm{T}_{\mathrm{d}} & =\text { computed daily max water temperature }{ }^{\circ} \mathrm{C} \\
\mathrm{T}_{s} & =\text { computed mean water temperature (May-Sept.) }{ }^{\circ} \mathrm{C} \\
\mathrm{I} & =\text { watershed imperviousness }(\%)
\end{aligned}
$$

The relation between them is very close: $\mathrm{R}^{2}$ is $0.9,0.96$ and 0.97 respectively. Standard errors are less than $5 \%, 2 \%$ and $3 \%$ respectively.

All three linear equations are plotted in Figure 8.1 and show some differences: the smaller the time step, the higher both the temperature and the enrichment. The relationships may vary with the watersheds, but watershed imperviousness is always positively correlated with water temperature. Non-linearity seems to increase with mean temperature.

Stream size is an important factor in thermal enrichment of receivers by urban stormwater. The impacts of thermal enrichment have been investigated in many small streams (Pluhowski 1970), and it is well established that temperature changes due to urbanization have more obvious effects on small streams than on bigger rivers. The relationships between water temperature and watershed imperviousness for May to September established by both Galli (1990) and our computation in the Speed River shows respectively:

Galli: mean summer water temperature $\left({ }^{\circ} \mathrm{C}\right)=15.8+0.076 \mathrm{I}$

This study:

$$
\mathrm{T}_{\mathrm{s}}=17.0+0.01 \mathrm{I}
$$

The former relation was observed in rivers less than 3 meters wide; while the latter was computed for a river about 30 meters wide. This may indicate that the base water temperature in larger rivers is higher than for smaller streams, and that water temperatures in smaller streams are more sensitive to imperviousness 


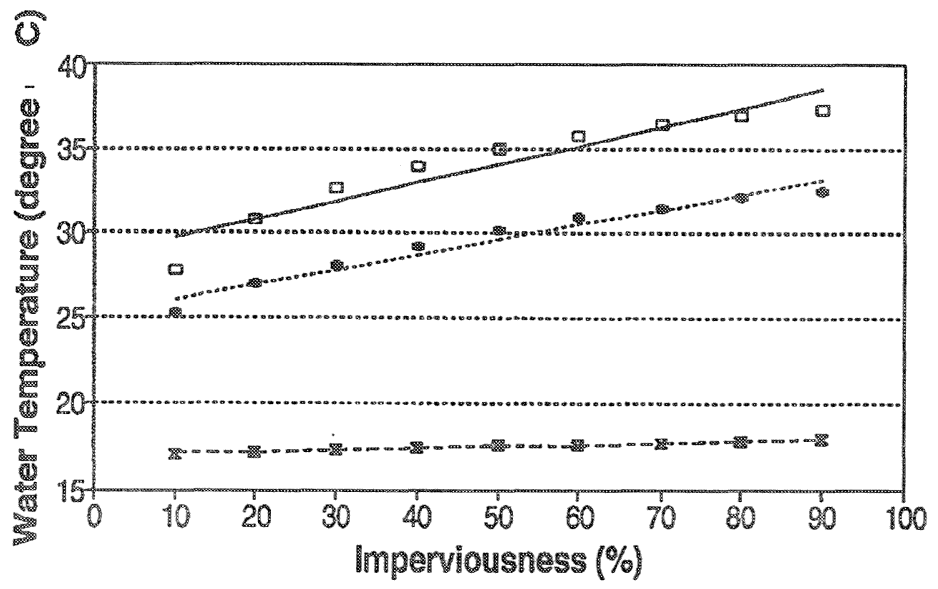

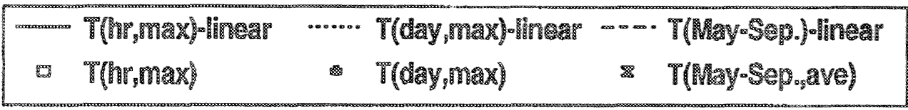

Figure 8.1 Water temperature as a function of \% imperviousness.

(expressed as \%). Model errors include such factors as unexplained processes; shading cover as a percentage; imperviousness types (e.g. color and thermal capacity of pavement); urban stormwater infrastructure; rainfall distribution; accuracy of observed data; and groundwater exfiltration. Calibration could be improved by using a 3 to 5 year record of continuous data. Moore (1967) found that the mean monthly water temperature during the summer does exceed mean monthly air temperature for the same streams while for many others the temperatures are significantly lower than air temperature. Generally, those streams that are exposed to direct sunlight tend to have mean monthly temperatures that exceed mean monthly air temperatures (which, of course, are taken in the shade). The monthly mean Speed River water temperatures values are higher than air temperatures, probably implying that the river has little canopy, is exposed and absorbs much solar radiation.

The HSPF model has no codes for modeling thermal enrichment of urban stormwater as runoff-transport process, so several adjustments were used in our modeling procedures. Input parameters for calculating temperature of runoff from impervious surfaces were estimated using the results of our experiments in the parking lot. The ensuing results of the re-calibrated model were better than those obtained running the model with the recommended assumptions. Recall that observed parking lot runoff temperatures were approximately 3 to $4^{\circ} \mathrm{C}$ higher than air temperatures. 


\subsection{Conclusions}

HSPF is the only comprehensive model of watershed hydrology and water quality that allows the integrated simulation of land and soil contaminant runoff processes with instream hydraulic, water temperature, sediment transport, nutrient, and sediment-chemical interactions (Donigian and Huber, 1991).

In our Speed River water temperature simulation, the following steps were taken:

1. select the simulation target;

2. determine the time step to be used in the simulation;

3. collect all the data needed for segmentation, which included: land use, catchment topographic map, watershed soil type and meteorological TS data;

4. choose modules and sections of HSPF to be used in the simulation;

5. carry out detailed sensitivity analysis and calibration; and

6. validate the calibrated model against other, known conditions.

Preparing the time series input data is a difficult procedure. The TSS (time series store), which stores all time series data for model running, is like a black box, in which the user cannot directly see the contents. The data format required by HSPF is not free and necessitates cautiously setting the required precise data file formats to avoid errors in TSS and program runs.

Preliminary knowledge of HSPF operations will allow the user to eliminate much of the cost and frustration involved in a trial-and-error approach to running the model. The user Control Input File was a key step in running HSPF, and the fourteen test files given in the program provide very good examples. HSPF supplies error message files which allow the user to check the possible mistakes. The output from HSPF can be easily controlled by the user, and a variety of output levels and formats selected. Some errors are not detected in the file, such as subroutine operations in the wrong order; computer hardware improperly set, or input files in an incorrect format. These mistakes may be avoided by carefully reading the user manual and following the run trail.

Model application cannot be accurate all of the time. Possible errors in the modeling include:

1. The observed data. Continuous water temperature data were supplied by the GRCA, the water being pumped through a pipe, which may cause the observed temperature to be higher than the actual stream water temperature.

2. Process simplifications. The HSPF model is a one-dimensional model, which assumes that each reach is completely mixed. This is not true in reality, especially when the stream is wide and deep.

3. The water temperature in the outflow from the impervious segment is estimated in the IWTGAS section of the IMPLND module in the HSPF model by the following regression equation: 


$$
\text { SOTMP }=\text { AWTF + BWTF*AIRTC }
$$

where:

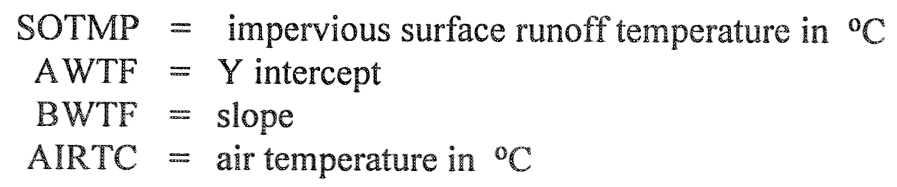

Parameters AWTF and BWTF may be input on a monthly basis. From the experiment of April 6th, 1993, impervious surface runoff temperatures (SOTMP) and air temperatures (AIRTC) were tested by thermocouples. Our results demonstrated a poor linear relation between air and runoff temperatures even when anomalous data are filtered out $\left(R^{2}=0.63\right)$. In particular, we observed no linear relation between air and runoff temperatures at the onset of runoff.

4. Lack of experience. There were not many HSPF model applications available for reference, particularly water temperature simulations. There have been no attempts to model thermal enrichment. This lack of experience for temperature modeling contributes to the difficulties of proper parameter selection.

5. In this study, the data used for upstream water temperature input TS were collected monthly, which means that the water temperature inputs are monthly averaged. The simulation interval on the other hand was one hour. Such averaging is considered to be unacceptable.

6. The time distribution of rainfall during a storm affects the time distribution of runoff from small watersheds. A point measurement of rainfall is not representative of areas in excess of a few square kilometres. Average rainfall intensity tends to vary inversely with the area covered, and it is necessary for many design purposes to quantify the depth-area relationship characteristics of a single storm or of all storms in a climatic region (Dunne and Leopold, 1978). Because time and spatial distributions of storms are often unknown, the impacts of that storm are difficult to quantify. Storms that occur at different times will have different impacts on temperature; if it rains when the pavement is hot, the water temperature may increase; but if it rains during a cool night, the impact will not be significant. Indeed it may be beneficial. A heavy storm transports more heat; but the temperature of runoff may drop after a certain time. An uneven spatial distribution of the storm also plays an important role in stormwater management. More observations and analyses are required. 
Main conclusions to be drawn from this study are:

1. thermal enrichment is closely related to imperviousness;

2. HSPF can be used to simulate the thermal enrichment of the Speed River at Guelph;

3. significant improvements of computed stream temperatures are possible if parameters are estimated from field experiments; and

4. coding the runoff heat process is a promising approach for simulating thermal enrichment.

Available simulation models do not consider heat washed off by stormwater. Quantifying the heat carried into a receiver from hot pavement is certainly an important need for future model applications in urban planning and development. Runoff temperature is clearly affected by pavement temperature at the onset of storms and by rainfall rates; air temperature is linked to the pavement temperature less directly; and for each watershed, stream temperature enrichment is related to the percentage areal imperviousness.

Coding algorithms for heat accumulated in the pavement surface and heat transport from pavement into the receiver are future tasks. The authors suggest that FORTRAN codes be written and linked with other temperature models such as HSPF, or SWMM. More field measurements are necessary in order to better define the heat flux processes. No urban surface water quality model can perform well without calibration. The more accurate the field data, the better the model result will be. It is important to measure temperature upstream and downstream of Guelph at the sewage discharge outfall, and at outfalls from parking lots and highways. The existing temperature recorders should be checked frequently.

When the input time series data become available, a fine time resolution is needed in modeling stormwater temperature, as storms may occur suddenly and last only a few minutes during hot weather, rather than over hours, or days.

\section{Acknowledgments}

This chapter was put together by Bill. Jenny did all the original hard work, and presented it for an MSc degree at the U of Guelph (Xie, 1993). Bill provided the original research ideas, advisement, facilities and support funds through his research operating grants, and finally wrote the article from Jenny's much longer dissertation. Rob Johanson, to whose memory this monograph is dedicated, was an invaluable advisor.

\section{References}

Chow, Ven Te, Eliassen, R., and.Linsley, R. K, 1979. Modeling and Control of River Quality. McGraw-Hill Series in Water Resources and Environmental Engineering. 
Donigian, A. and Crawford, N. 1976. Modeling Nonpoint Pollution from The Land Surface. USEPA, Office of Research and Development Environmental Research Laboratory. 280pp.

Donigian, A. and Davis, H. 1978. Agricultural Runoff Management (ARM) Model USEPA, Office of Research and Development Environmental Research Laboratory. $163 \mathrm{pp}$.

Donigian, A., Imhoff, J. and Bicknell, B. 1983. Predicting Water Quality Resulting from Agricultural Nonpoint Source Pollution via Simulation -HSPF. Agricultural Management and Water Quality. IOWA State University Press. 200-249pp.

Donigian, A., Imhoff, J.C., Bicknell, B.R. and Kittle, J.L. 1984. Application Guide For Hydrological Simulation Program - Fortran (HSPF). USEPA, Office of Research and Development Environmental Research Laboratory. 177pp.

Donigian, A. and Huber, W. C. 1991. Modeling of Nonpoint Source Water Quality in Urban and Non-urban Areas. Environmental Research Lab., Office of Research and Development, USEPA. 72pp.

Dunne, T. and Leopold L. B. 1978. Water in Environmental Planning. W.H. Freeman and Company. 818pp.

Galli, J. 1990. Thermal Impacts Associated with Urbanization and Stormwater Management Best Management Practices. Metropolitan Washington Council of Governments. $157 \mathrm{pp}$.

Gray, J.R.A. and Edington, J.M. 1969. Effect of Woodland Clearance on Stream Temperature. J. Fish Res. Bd. Canada. 26:399-403.

Hewlett, J.D. and Fortson, J.C. 1982. Stream Temperature Under An Inadequate buffer strip in the Southeast Piedmont. Water Res. Bull. 18(6): 983-988.

Huber W.C. 1992. Prediction of Urban Nonpoint Source Water Quality: Method and Models. International Symposium on Urban Stormwater Management, Sydney, 4-7 Feb., 1992. 16pp.

Huber W. and Dickinson R. E. 1988. Stormwater Management Model, Version 4: User's Manual. Environmental Research Laboratory, Office of Research and Development, USEPA. 569pp.

James, W. and Boregowda, S. 1985. Continuous Mass Balance of Pollutant Built-up Processes. Urban Runoff Pollution, H.C. Torno, J. Marsalek and M. Desbordes, eds., NATO ASI Series, Series G: Ecological Science, Vol. 10, Springer-Verlag, New York, 1985, pp. 243-271.

James, W. and B. Verspagen. 1996. "Thermal Enrichment of Stormwater by Urban Pavement." Journal of Water Management Modeling R195-08. doi: 10.14796/JWMM.R195-08.

Johanson, R.C., Imhoff, J.C, Kittle, J.L., and Donigian, A.S. 1984. Hydrological Simulation Program -Fortran (HSPF): User Manual. USEPA. EPA-600/9-80-015. 767pp.

Klein, R.O. 1979. Urbanization and Stream Quality Impairment. Water Resources Bulletin, 15(4): 948-963.

McCutcheon, Steve C. 1989. Water Quality Modeling. Volume 1, Transport and Surface Exchange in Rivers. CRC Press, Inc. Boca Raton, Florida. 272pp.

Moore, A. M. 1967. Correction and Analysis of Water-Temperature Data For Oregon Streams. Geological Survey Water-Supply Paper 1819-K, 53pp.

Picksley, W. and A. Deletic. 1998. "The Thermal Enrichment of Storm Runoff from Paved Areas - a Statistical Analysis." Journal of Water Management Modeling R204-07. doi: 10.14796/JWMM.R204-07. 
Pluhowski, E.J. 1970. Urbanization and Its Effect on the Temperature of the Streams on Long Island, New York. U.S. Geological Survey Professional Paper 627-D, $110 \mathrm{pp}$. Shanahan, Peter. 1984. Water temperature Modeling: A Practical Guide. US Environmental Protection Agency Proceeding of Stormwater and Water Quality Model Users Group Meeting, April 12-13, 1984.

Statistics Canada Census Divisions and Subdivisions. 1991. Population Dwelling Towns.CP Catalog No. 93-304.

Xie, J. D. M., 1993. Thermal enrichment of urban stormwater. .MSc thesis, Univ of Guelph, Canada.

Xie, D.M. and W. James. 1994. "Modelling Solar Thermal Enrichment of Urban Stormwater." Journal of Water Management Modeling R176-13. doi: 10.14796/JWMM.R176-13. 
